\title{
Cytogenetic and symbiont analysis of five members of the B. dorsalis complex (Diptera, Tephritidae): no evidence of chromosomal or symbiont-based speciation events
}

\author{
Antonios A. Augustinos 1,2,3, Elena Drosopoulou ${ }^{4}$, Aggeliki Gariou-Papalexiou', \\ Elias D. Asimakis ${ }^{3}$, Carlos Cáceres², George Tsiamis ${ }^{3}$, Kostas Bourtzis², \\ Penelope Mavragani-Tsipidou ${ }^{4}$, Antigone Zacharopoulou'
}

\begin{abstract}
I Department of Biology, University of Patras, Patras, Greece 2 Insect Pest Control Laboratory, Joint FAO/ IAEA Programme of Nuclear Techniques in Food and Agriculture, Seibersdorf, Vienna, Austria 3 Department of Environmental and Natural Resources Management, University of Patras, Agrinio, Greece 4 Department of Genetics, Development and Molecular Biology, School of Biology, Faculty of Sciences, Aristotle University of Thessaloniki, Thessaloniki, Greece
\end{abstract}

Corresponding author: Antigone Zacharopoulou (zacharop@upatras.gr)

Academic editor: A. Clarke | Received 23 April 2015 | Accepted 20 July 2015 | Published 26 November 2015

http://zoobank.org/A3099847-4671-4F55-BB1D-5381942EC012

Citation: Augustinos AA, Drosopoulou E, Gariou-Papalexiou A, Asimakis ED, Cáceres C, Tsiamis G, Bourtzis K, Mavragani-Tsipidou P, Zacharopoulou A (2015) Cytogenetic and symbiont analysis of five members of the B. dorsalis complex (Diptera, Tephritidae): no evidence of chromosomal or symbiont-based speciation events. In: De Meyer M, Clarke AR, Vera MT, Hendrichs J (Eds) Resolution of Cryptic Species Complexes of Tephritid Pests to Enhance SIT Application and Facilitate International Trade. ZooKeys 540: 273-298. doi: 10.3897/zookeys.540.9857

\begin{abstract}
The Bactrocera dorsalis species complex, currently comprising about 90 entities has received much attention. During the last decades, considerable effort has been devoted to delimiting the species of the complex. This information is of great importance for agriculture and world trade, since the complex harbours several pest species of major economic importance and other species that could evolve into global threats. Speciation in Diptera is usually accompanied by chromosomal rearrangements, particularly inversions that are assumed to reduce/eliminate gene flow. Other candidates currently receiving much attention regarding their possible involvement in speciation are reproductive symbionts, such as Wolbachia, Spiroplasma, Arsenophonus, Rickettsia and Cardinium. Such symbionts tend to spread quickly through natural populations and can cause a variety of phenotypes that promote pre-mating and/or post-mating isolation and, in addition, can affect the biology, physiology, ecology and evolution of their insect hosts in
\end{abstract}

Copyright Antonios A Augustinos et al. This is an open access article distributed under the terms of the Creative Commons Attribution License (CC BY 4.0), which permits unrestricted use, distribution, and reproduction in any medium, provided the original author and source are credited. 
various ways. Considering all these aspects, we present: (a) a summary of the recently gained knowledge on the cytogenetics of five members of the $B$. dorsalis complex, namely $B$. dorsalis s.s., B. invadens, $B$. philippinensis, $B$. papayae and $B$. carambolae, supplemented by additional data from a $B$ dorsalis s.s. colony from China, as well as by a cytogenetic comparison between the dorsalis complex and the genetically close species, $B$. tryoni, and, (b) a reproductive symbiont screening of 18 different colonized populations of these five taxa. Our analysis did not reveal any chromosomal rearrangements that could differentiate among them. Moreover, screening for reproductive symbionts was negative for all colonies derived from different geographic origins and/or hosts. There are many different factors that can lead to speciation, and our data do not support chromosomal and/or symbiotic-based speciation phenomena in the taxa under study.

\section{Keywords}

Tephritidae, Wolbachia, inversions, polytene chromosomes

\section{Introduction}

The Bactrocera dorsalis species complex currently consists of approximately 90 entities, whose limits are not fully resolved (Drew and Hancock 1994, Drew and Romig 2013, Krosch et al. 2013, Boykin et al. 2014, Schutze et al. 2015). However, species delimitation is of paramount importance when dealing with economic important species, since it can influence world trade through implementation of quarantine policies and/or facilitate the application of species specific, environmental friendly control methods, such as the Sterile Insect Technique (SIT). Driven by these considerations, much effort has been invested in the last decades to clarify the species status within the complex. Among the most recent advances in this area, Drew and Romig (2013) synonymised $B$. papayae and B. philippinensis under B. papayae, while Schutze and colleagues (Scutze et al. 2015) have proposed the further synonymization of these two taxa and B. invadens with $B$. dorsalis s.s., under $B$. dorsalis s.s.

Recent studies have shown that efforts to resolve complex species status require multidisciplinary approaches (De Queiroz 2007, Schlick-Steiner et al. 2010), wellcharacterized material and extended sampling (Schutze et al. 2012, Krosch et al. 2013, Boykin et al. 2014). Such approaches have been also followed in other Tephritidae genera where species delimitation of species complexes is also an important concern, such as in Anastrepha (Selivon et al. 2005, Vera et al. 2006, Cáceres et al. 2009). This is due to the fact that speciation can be driven by a variety of forces, resulting in different speciation paths. The data basis can be complicated when speciation is ongoing (incipient). Therefore, in collaboration and through independent analysis, different research groups around the world, through the Coordinated Research Program: 'Resolution of Cryptic Species Complexes of Tephritid Pests to Enhance SIT Application and Facilitate International Trade' have accumulated a multitude of data that have contributed to the better understanding of the Tephritidae species complexes. One of the main targets was the resolution among five economic important taxa with unclear limits within the $B$. dorsalis complex. These were $B$. dorsalis s.s., $B$. papayae, $B$. philippinensis, B. invadens and B. carambolae. 
A key pathway of speciation in Diptera is through chromosomal rearrangements (CRs), mainly inversions. More than fifty years of research on polytene chromosomes of Drosophila and mosquito species have shown that speciation is almost universally accompanied with inversions (Sturtevant and Dobzhansky 1936, Ashburner et al. 1982, Krimbas and Powell 1992, Noor et al. 2001, Rieseberg 2001, Kirkpatrick and Barton 2006, Bhutkar et al. 2008, Kulathinal et al. 2009, Stevison et al. 2011, Lee et al. 2013). The recent advances in whole genome sequencing and the availability of a number of genomes of Drosophila and mosquito species have verified the nuclear DNA rearrangements described in earlier cytogenetic studies (Kirkpatrick and Barton 2006, Ranz et al. 2007, Bhutkar et al. 2008, Schaeffer et al. 2008, Kulathinal et al. 2009, McGaugh and Noor 2012, Lee et al. 2013). Different models have been proposed to explain how CRs enhance speciation, recently focusing mainly on the restriction of recombination within and near inverted regions as the causal factor of restriction in gene flow (Noor et al. 2001, Rieseberg 2001, Kirkpatrick and Barton 2006, Faria and Navarro 2010).

However, sequencing of entire genomes cannot yet be easily applied to species with bigger genomes and a high proportion of repetitive DNA sequences. Shotgun sequencing approaches are relatively quick and cheap, but cannot provide insight into higher chromosomal organization of species lacking of a complete sequenced reference genome, at least up to now. Regarding the $B$. dorsalis complex, the draft genome of $B$. dorsalis s.s. currently consists of more than 86,000 contigs (http://www.ncbi. nlm.nih.gov/assembly/GCF_000789215.1). Even though the construction of several genome databases of Tephritidae species is ongoing, this methodology is so far (a) too slow and expensive to screen a large number of different populations and (b) it is not guaranteed to reveal structural chromosomal changes between species, unless coupled with molecular and genetic approaches, such as Sanger sequencing, cloning and in situ hybridization. Direct observation and comparison of chromosomes is still a very powerful approach to shed light on the higher organization and structure of chromosomes. Although mitotic chromosomes can also provide some information, polytene chromosomes are an excellent tool for resolution of CRs.

In Tephritids, there is a number of studies presenting and discussing mitotic karyotypes, especially for Bactrocera (Hunwattanakul and Baimai 1994, Baimai et al. 1995, 1999, 2000, Baimai 1998, 2000), Anastrepha (Cevallos and Nation 2004, Selivon et al. 2005, Goday et al. 2006, Selivon et al. 2007) and Rhagoletis species (Bush and Boller 1977). However, useful polytene chromosome maps, so far available for five genera, represent only 11 species: one of Anastrepha (A. ludens) (Garcia-Martinez et al. 2009), one of Ceratitis (C. capitata) (Zacharopoulou 1990), one of Dacus (D. ciliatus) (Drosopoulou et al. 2011b) and three of Rhagoletis, namely $R$. cerasi (Kounatidis et al. 2008), $R$. cingulata (Drosopoulou et al. 2011a) and $R$. completa (Drosopoulou et al. 2010). The genus Bactrocera can be regarded as the best studied so far, including four species of three different subgenera. These are B. oleae (subgenus Daculus) (Mavragani-Tsipidou et al. 1992), B. cucurbitae (subgenus Zeugodacus) (Zacharopoulou et al. 2011b) and B. dorsalis s.s. (Zacharopoulou et al. 2011a) plus B. tryoni (subgenus Bactrocera) (Zhao et al. 1998). 
Cytogenetic studies have been used to distinguish between different members of the $B$. dorsalis complex in the past, based on mitotic chromosomes. Hunwattanakul and Baimai (1994) presented the typical karyotype of $B$. dorsalis, which is being referred to as form $A$. The mitotic karyotype of the complex is $2 n=12$, consisting of five pairs of autosomes and a heterogametic XX/XY sex chromosome pair. In the following years, Baimai and colleagues presented numerous species within the complex with distinct mitotic karyotypes (Baimai et al. 1995, 2000, Baimai 1998). Although these studies are of great importance and reveal the power of cytogenetics for the resolution of species limits within species complexes, they suffered from limitations that could not be addressed or even predicted in the previous years. These include (a) the ongoing debate on species limits and taxonomy of the complex, (b) utilization of material from the field that cannot be evaluated with other approaches, since it was not colonized and, (c) lack of robust diagnostic tools within this complex. All these indicate that older taxonomic conclusions should be used with care and seen in the light of recent advances in the field.

To overcome such constraints, recent cytogenetic studies have used laboratory colonies from the Joint FAO/IAEA Insect Pest Control Laboratory (IPCL). These colonies are also material in a variety of research programs, are always available for further analyses and their status is routinely verified by expert taxonomists. Zacharopoulou and colleagues analysed colonized material of $B$. dorsalis s.s., derived from Thailand and from a Genetic Sexing Strain (GSS) constructed in Hawaii (Zacharopoulou et al. 2011a). In this study, the form A mitotic karyotype was verified for B. dorsalis s.s., and polytene chromosome map for this species was constructed, which includes 10 polytene arms. These arms correspond to the autosomes, which is consistent with the already described non-polytenization of the sex chromosomes in Tephritidae (Zacharopoulou 1990, Mavragani-Tsipidou et al. 1992, Zhao et al. 1998, Garcia-Martinez et al. 2009, Drosopoulou et al. 2010, Zacharopoulou et al. 2011a, Zacharopoulou et al. 2011b, Drosopoulou et al. 2011a, Drosopoulou et al. 2011b, Drosopoulou et al. 2012). Recently, a more extended cytogenetic analysis was performed (Augustinos et al. 2014b), shedding more light on the resolution of the species limits of the five taxa described before. Six laboratory colonies, representing $B$. dorsalis s.s. (two colonies), $B$. papayae, B. philippinensis, B. invadens and B. carambolae, were examined (Table 1) and all exhibited the form A mitotic karyotype. This was quite a surprise, since it is not in agreement with previous studies, where a distinct karyotype with a quite large $\mathrm{X}$ chromosome, carrying an 'elongated' arm with a secondary constriction, was described for B. carambolae from Thailand (Baimai et al. 1999). In addition, polytene chromosomes did not reveal any fixed CRs among these five taxa that could be used as diagnostic markers (Augustinos et al. 2014b).

A second factor that should not be overlooked in studies addressing speciation phenomena is the presence of specific symbiotic bacteria, especially those referred to as 'reproductive parasites'. These are symbiotic bacteria mainly found in reproductive tissues and are best known to interfere with host reproduction, inducing a variety of phenotypes such as male killing, parthenogenesis, feminization and Cytoplasmic 
Table I. Material used in the present study.

\begin{tabular}{|c|c|c|c|c|c|}
\hline \multirow[t]{2}{*}{ No } & \multirow[t]{2}{*}{ Species } & \multirow[t]{2}{*}{ Origin } & \multicolumn{2}{|c|}{$\begin{array}{c}\text { Reproductive } \\
\text { symbiont } \\
\text { screening* }\end{array}$} & \multirow[t]{2}{*}{ Cytogenetically analyzed } \\
\hline & & & $\mathbf{M}$ & $\mathbf{F}$ & \\
\hline 1 & B. dorsalis & Saraburi, Thailand & 10 & 10 & $\begin{array}{l}\text { Zacharopoulou et al. 2011a } \\
\text { Augustinos et al. 2014b }\end{array}$ \\
\hline 2 & B. dorsalis & $\begin{array}{c}\text { Nakhon Sri Thammarat, } \\
\text { Thailand }\end{array}$ & 10 & 10 & Augustinos et al. 2014b \\
\hline 3 & B. dorsalis G17 & Bangkok, Thailand & 10 & 10 & \\
\hline 4 & B. dorsalis GSS & Hawaii & 10 & 10 & $\begin{array}{c}\text { Zacharopoulou et al. 2011a; } \\
\text { Zacharopoulou and Franz } 2013\end{array}$ \\
\hline 5 & $\begin{array}{l}\text { B. dorsalis } \\
\text { (White body) }\end{array}$ & OAP, Bangkok, Thailand & 10 & 10 & \\
\hline 6 & B. dorsalis & Yunnan, China & 10 & 10 & \\
\hline 7 & B. dorsalis & Fujian, china & 10 & 10 & \\
\hline 8 & B. dorsalis & Pakistan & 10 & 10 & \\
\hline 9 & B. dorsalis & Myanmar & 10 & 10 & \\
\hline 10 & B. dorsalis & India & 10 & 10 & \\
\hline 11 & B. dorsalis & Wuhan, China (colony 1) & 10 & 10 & Present study \\
\hline 12 & B. dorsalis & Wuhan, China (colony 2) & 10 & 10 & \\
\hline 13 & B. carambolae & $\begin{array}{l}\text { Paramaribo, } \\
\text { Suriname }\end{array}$ & 10 & 10 & Augustinos et al. 2014b \\
\hline 14 & B. carambolae & Serdang, Malaysia & 10 & 10 & \\
\hline 15 & B. philippinensis & Guimaras Island, Philippines & 10 & 10 & \\
\hline 16 & B. philippinensis & Philippines & 10 & 10 & Augustinos et al. 2014b \\
\hline 17 & B. papayae & $\begin{array}{l}\text { Serdang, } \\
\text { Malaysia }\end{array}$ & 10 & 10 & Augustinos et al. 2014b \\
\hline 18 & B. invadens & Kenya & 10 & 10 & Augustinos et al. $2014 \mathrm{~b}$ \\
\hline 19 & B. tryoni & Australia & 10 & 10 & Present study \\
\hline
\end{tabular}

*Twenty flies were screened for the presence of the five reproductive symbionts listed in Table 2. None was positive for none of the symbionts.

Incompatibility (CI). Among them, Cardinium, Arsenophonus, Spiroplasma, Rickettsia and Wolbachia are commonly found in different arthropods (Bourtzis and Miller 2003, 2006, 2009, Perlman et al. 2006, Duron et al. 2008a, Werren et al. 2008, Saridaki and Bourtzis 2010, Zchori-Fein and Bourtzis 2011).

Wolbachia is probably the most ubiquitous bacterial symbiont in insects (Hilgenboecker et al. 2008, Zug and Hammerstein 2012) and is regarded as a putative 'speciation agent', since it can restrict gene flow through (CI) and lead to the selection and fixation of specific genotypes in a population. Wolbachia-induced CIs can co-exist with local selection on alleles involved in incompatibilities and, therefore, increase the migration rates that genetic variability can experience without getting lost. The combined act of the two aforementioned forces of incompatibility can lead to maintenance of the divergence among populations and enhance speciation (Flor et al. 2007, Telschow 
et al. 2007, 2014). Besides theoretical and model predictions, the implication of Wolbachia in pre- and / or post-mating isolation phenomena has been experimentally supported in different insect systems including the parasitic wasps of the genus Nasonia (Bordenstein et al. 2001, Bordenstein and Werren 2007) and Drosophila (Jaenike et al. 2006, Koukou et al. 2006, Miller et al. 2010).

In tephritids, most studies have so far focused on the detection and characterization of Wolbachia infections. Although screening is far from complete, well-established infections have been found in some species. The best characterized species is $R$. cerasi, since all natural populations studied so far are $100 \%$ infected, usually with multiplestrain infections (Riegler and Stauffer 2002, Kounatidis et al. 2008, Arthofer et al. 2009, Augustinos et al. 2014a, Karimi and Darsouei 2014). More importantly, it is a well-documented example of the implication of Wolbachia in restriction in gene flow and enhancement of incompatibility between natural populations of the species (Riegler and Stauffer 2002). Other Rhagoletis species that seem to have persistent and multiple strain infections (although less populations are studied) are $R$. pomonella (Schuler et al. 2011) and $R$. cingulata (Drosopoulou et al. 2011a, Schuler et al. 2013), along with some Rhagoletis species of Japan (Coats et al. 2013). Outside Rhagoletis, the only species demonstrating persistent Wolbachia infections is $A$. fraterculus, (Selivon et al. 2002, Cáceres et al. 2009, Coscrato et al. 2009, Marcon et al. 2011, Martinez et al. 2012). All other tephritid species are so far considered as Wolbachia-free or only exhibiting low prevalence infections. Among them, C. capitata is also considered as Wolbachia-free (Bourtzis et al. 1994, Zabalou et al. 2004); however, there are two reports from a research group in Latin America discussing the presence of Wolbachia in local populations of the species (Rocha et al. 2005, Coscrato et al. 2009). The recent study on the Wolbachia presence in Australian fruit flies (Morrow et al. 2015) has extended our knowledge on the Wolbachia status of Tephritidae in a relatively unexplored area. In accordance with previous studies, few species were found infected and only a relatively small (although varying) percentage of individuals. However, this study demonstrated the presence of different Wolbachia strains, shared among natural populations of different species, raising the possibility of recent horizontal transmission events through shared parasitoids. Regarding the other four symbionts, there are up to now no reports of infected populations, at least to our knowledge. Especially for the $B$. dorsalis complex, there are only three reports of Wolbachia infections in natural populations. In all these cases, infections were found at a very low prevalence in nature (Kittayapong et al. 2000, Jamnongluk et al. 2002, Sun et al. 2007).

The purpose of this study was to (a) summarize gained knowledge and (b) provide new evidence regarding the cytogenetic and symbiotic status of the $B$. dorsalis complex, with the aim to identify factors possibly involved in speciation. Focus has been given on five taxa of economic importance and unclear species limits, namely $B$. dorsalis s.s., B. papayae, B. philippinensis, B. invadens and B. carambolae. Only material colonized at the Joint FAO/IAEA IPCL was analysed, that was also used in other Joint FAO/IAEA IPCL research programs (Wee et al. 2002, Krosch et al. 2013, Boykin et al. 2014, Schutze et al. 2013, Tan et al. 2013, Bo et al. 2014). More specifically, our cytogenetic 
analysis was extended to (a) a B. dorsalis s.s. population derived from China, a cytogenetically unexplored area of great interest for the complex, (b) a new Australian colony of $B$. tryoni, a species that is genetically discrete though not phylogenetically distant from the $B$. dorsalis complex and (c) F1 bidirectional hybrids of $B$. dorsalis s.s. and $B$. tryoni. In addition, an extensive PCR screening was performed aiming at the detection of the five aforementioned reproductive symbionts in 18 different colonies available for the dorsalis complex and the colony representing B. tryoni (Table 1).

\section{Methods}

\section{Material used}

Nineteen colonies currently kept at the Joint FAO/IAEA IPCL were screened for the presence of different reproductive symbionts (Table 1). Eighteen of them represent the five members of the complex under discussion (B. dorsalis s.s., B. papayae, B. philippinensis, $B$. invadens and $B$. carambolae), while one colony represents $B$. tryoni from Australia that was included as a closely related outgroup. Two colonies were cytogenetically analysed (B. dorsalis s.s. from China-Wuhan and B. tryoni from Australia) and were added to the seven colonies previously analysed (see Table 1 and references therein). The $\mathrm{F}_{1}$ bidirectional hybrids of $B$. dorsalis s.s. $\times$ B. tryoni were also analysed.

\section{Mitotic chromosome preparations}

Chromosome preparations were made as described in Zacharopoulou (1990) and Mavragani-Tsipidou et al. (2014). Brain tissue was dissected in $0.7 \% \mathrm{NaCl}$, transferred to $1 \%$ sodium citrate on a well slide for at least $15 \mathrm{~min}$ and fixed in fresh fixation solution (methanol/acetic acid 3:1) for 3 min. Fixation solution was removed and a drop of acetic acid $(60 \%)$ was added. Tissue was dispersed using a micropipette and the cell suspension was dried on a clean slide placed on a hotplate $\left(40-45^{\circ} \mathrm{C}\right)$. Chromosomes were stained with Giemsa (5\% Giemsa in $10 \mathrm{mM}$ phosphate buffer, pH 6.8). Chromosome slides were analysed at $100 \times$ magnification, using a phase contrast microscope (Leica DMR), and photographs were taken using a CCD camera (ProgRes CFcool; Jenoptik Jena Optical Systems, Jena, Germany). At least 15 good quality preparations per sample and at least 10 well-spread nuclei per preparation were analysed.

\section{Polytene chromosome preparations}

Polytene chromosome preparations were made from 3rd instar larvae, as described in Zacharopoulou (1990), Mavragani-Tsipidou et al. (2014). Larvae were dissected in acetic acid (45\%), and salivary glands were transferred to $\mathrm{HCl}(3 \mathrm{~N})$ for $1 \mathrm{~min}$, fixed 
in 3:2:1 fixation solution (3 parts acetic acid: 2 parts water: 1 part lactic acid) for -5 min (until transparent) and stained in 2\% lacto-aceto-orcein for 5-7 min. Glands were washed with 3:2:1 solution to remove excess stain and squashed. Chromosome slides were analysed at 100x magnification using a phase contrast microscope (Leica DMR) and photographs were taken using a CD camera (ProgRes CFcool; Jenoptik Jena Optical Systems, Jena, Germany). At least 15 good quality preparations per sample and at least 10 well spread nuclei per preparation were analysed.

\section{DNA extraction and PCR screening for reproductive symbionts}

DNA was extracted from single flies, using the CTAB protocol (Doyle and Doyle 1990). To verify DNA quality, PCRs were performed for randomly selected samples with the universal primer pair 12SCFR/12SCRR that amplifies $420 \mathrm{bp}$ of the insect mitochondrial $12 \mathrm{~S}$ rRNA gene (Hanner and Fugate 1997). In total, 380 samples were screened for the presence of Wolbachia, Spiroplasma, Arsenophonus, Rickettsia and Cardinium. Screening was performed using bacterial species-specific $16 \mathrm{~S} r R N A$ gene-based PCR. Depending on the set of primers used, the amplified DNA fragment varied in size from $200 \mathrm{bp}$ to $611 \mathrm{bp}$. The amplification was performed in $20 \mu \mathrm{l}$ reactions, each containing $2 \mu$ l of $10 \times \mathrm{KAPA}$ Taq Polymerase Buffer A (with $1.5 \mathrm{mM}$ of $\mathrm{MgCl}_{2}$ at $1 \times$ ), $0.1 \mu \mathrm{l}$ of dNTPs $(25 \mathrm{mM}), 0.5 \mu \mathrm{l}$ of the forward primer $(25 \mu \mathrm{M}), 0.5 \mu \mathrm{l}$ of the reverse primer $(25 \mu \mathrm{M}), 0.1 \mu \mathrm{l}$ of KAPA Taq DNA Polymerase $(5 \mathrm{U} / \mu \mathrm{l}), 15.8 \mu \mathrm{l}$ of sterile double distilled water and $1 \mu \mathrm{l}$ of DNA. The PCR protocol included an initial 5 minute denaturation at $95^{\circ} \mathrm{C}$, followed by 35 cycles of 30 seconds at $95^{\circ} \mathrm{C}, 30$ seconds at the optimum melting temperature for each pair of specific primers, 1 minute at $72{ }^{\circ} \mathrm{C}$ and a final extension step of 10 minutes at $72^{\circ} \mathrm{C}$, with the exception of Wolbachia, where 30 cycles were used. The products were electrophoresed on a $1.5 \%$ agarose gel in order to determine the presence and size of the fragments. Primer pairs and PCR conditions are summarized in Table 2.

\section{Results and discussion}

As already stated in the Introduction, material colonized in IPCL was used in the present study. This is in the frame of utilizing multi-disciplinary approaches, using the same samples if possible, to contribute to the species resolution in the dorsalis complex (Schutze et al. 2015). For such approaches utilization of colonized, well-characterized material is essential. This is even more evident for cytogenetics, since live material is needed. On the other hand, results obtained from laboratory colonies must be verified in larger samples of different origin before elevating to species level. As it has been shown by different studies (Gilchrist et al. 2012; Parreño et al. 2014, Zygouridis et al. 2014), lab colonization is accompanied by an adaptation process including severe bottlenecks, hitch-hiking effects and extended inbreeding. This can affect the genetic 
Table 2. PCR screening for five reproductive symbionts.

\begin{tabular}{|c|c|c|c|c|}
\hline Genus & Primer 5'-3' & $\operatorname{Tm}^{\circ} \mathrm{C}$ & Product Size & Reference \\
\hline \multirow[t]{2}{*}{ Wolbachia } & $\begin{array}{l}\text { wspecF } \\
\text { YATACCTATTCGAAGGGATAG }\end{array}$ & $55^{\circ} \mathrm{C}$ & $438 \mathrm{bp}$ & Werren and Windsor 2000 \\
\hline & \begin{tabular}{|l|} 
wspecR \\
AGCTTCGAGTGAAACCAATTC
\end{tabular} & & & \\
\hline \multirow{4}{*}{ Spiroplasma } & 63F_CG & \multirow{4}{*}{$60^{\circ} \mathrm{C}$} & \multirow{4}{*}{$450 \mathrm{bp}$} & \multirow{4}{*}{$\begin{array}{l}\text { Mateos et al. } 2006 \\
\text { Fukatsu and Nikoh } 2000\end{array}$} \\
\hline & GCCTAATACATGCAAGTCGAACGG & & & \\
\hline & TKSSspR & & & \\
\hline & TAGCCGTGGCTTTCTGGTAA & & & \\
\hline \multirow{4}{*}{ Arsenophonus } & ArsF & \multirow{4}{*}{$56^{\circ} \mathrm{C}$} & \multirow{4}{*}{$611 \mathrm{bp}$} & \multirow{4}{*}{ Duron et al. $2008 \mathrm{~b}$} \\
\hline & GGGTTGTAAAGTACTTTCAGTCGT & & & \\
\hline & ArsR5 & & & \\
\hline & CCСTAAGGCACGYYTYTATCTCTAA & & & \\
\hline \multirow{4}{*}{ Rickettsia } & 16SA1 & \multirow{4}{*}{$55^{\circ} \mathrm{C}$} & \multirow{4}{*}{$200 \mathrm{bp}$} & \multirow{4}{*}{ Fukatsu and Nikoh 2000} \\
\hline & AGAGTTTGATCTGGCTCAG & & & \\
\hline & Rick16SR & & & \\
\hline & CATCCATCAGCGATAAATCTTTC & & & \\
\hline \multirow{4}{*}{ Cardinium } & CLO-f1 & \multirow{4}{*}{$-56^{\circ} \mathrm{C}$} & \multirow{4}{*}{$466 \mathrm{bp}$} & \multirow{4}{*}{ Gotoh et al. 2007} \\
\hline & GGAACCTTACCTGGGCTAGAATGTATT & & & \\
\hline & CLO-r1 & & & \\
\hline & GCCACTGTCTTCAAGCTCTACCAAC & & & \\
\hline
\end{tabular}

structure of the populations and, possibly, their symbiotic communities. Therefore, results derived from colonized material should be 'interpreted' wisely and in combination with the analysis of natural collections.

\section{Mitotic karyotypes - agreements and inconsistencies with older studies}

The $B$. dorsalis s.s. colony from China showed the B. dorsalis s.s. mitotic karyotype known as form $A$. This is the typical and probably ancestral karyotype of the dorsalis complex. The above, together with previous results, show that the Joint FAO/IAEA IPCL colonies, representing the five investigated taxa, possess the same mitotic karyotype (Zacharopoulou et al. 2011a, Zacharopoulou and Franz 2013, Augustinos et al. 2014b). Older studies (Baimai et al. 1999) describe a different karyotype for B. carambolae from Thailand. Although the $B$. carambolae colony analysed recently, available at the Joint FAO/IAEA IPCL (Augustinos et al. 2014b), was derived from a Suriname population, it is highly unlikely that the different origin is the explanation for this difference. Incorrect species identification due to the limitations discussed in the Intro- 
duction Section is the most probable explanation. This is further supported by the fact that an independent study on the mitotic karyotypes of $B$. carambolae from Malaysia also found the typical form A karyotype for this taxon (Yesmin and Clyde 2012).

The examination of new material representing B. tryoni from Australia was in accordance with the previously published mitotic karyotype for this species (Zhao et al. 1998). This karyotype has five pairs of autosomes and a heterogametic XX/XY sex chromosome pair. The three larger autosome pairs are metacentric to submetacentric, while the two shorter autosome pairs are submetacentric to acrocentric. $Y$ is the smallest of the set, while $\mathrm{X}$ is large and probably larger than or comparable to the largest autosomes.

\section{Polytene chromosome comparisons and species resolution}

Polytene chromosome nuclei of $B$. dorsalis s.s. from China are shown in Figure 1. Its polytene chromosomes show the same banding pattern with the published maps of B. dorsalis s.s. (Zacharopoulou et al. 2011a), and therefore can be regarded as homosequential with all other colonies analysed so far (Augustinos et al. 2014b). The characteristic asynapsis at regions 73-74 of arm 5R previously observed in all colonies (Zacharopoulou et al. 2011a, Augustinos et al. 2014b) was also found here at a relatively high frequency (Figure 2). Its polymorphic presence in all colonies analysed so far points to the close genetic proximity of these five taxa.

Another interesting finding from the analysis of the China colony is the high presence of an asynapsis at the telomeric region of 3L (Figure 3). Although previously observed in other colonies (Zacharopoulou et al. 2011a, Augustinos et al. 2014b), its frequency in the specific colony is much higher than in the colonies analysed before. Again, this can be considered as an inter species, intra population variation.

In the recent proposed revisions that synonymize four out of the five Dorsalis taxa under study (Drew and Romig 2013, Schutze et al. 2015), B. carambolae is maintained as a distinct species within the complex, but closely related to $B$. dorsalis s.s. The recent cytogenetic analysis on these five taxa failed to find any fixed diagnostic CRs among $B$. dorsalis s.s. and B. carambolae (Augustinos et al. 2014b). However, as discussed in that paper, the high frequency of small asynapses observed in the $B$. dorsalis s.s. $\times B$. carambolae $\mathrm{F}_{1}$ hybrids, in comparison to the $B$. dorsalis s.s. $\times$ B. invadens $\mathrm{F}_{1}$ hybrids could be an indication of the presence of small CRs between the $B$. dorsalis s.s. and $B$. carambolae genomes, undetected with microscopy.

To explore the limitations of cytogenetic analysis in species resolution, we performed a polytene chromosome comparison between the dorsalis complex and B. tryoni, a species also belonging to the subgenus Bactrocera and routinely used as a closely related outgroup in different studies (Krosch et al. 2012; Boykin et al. 2014; Virgilio et al. 2015). To do so, polytene chromosome squashes from an IPCL laboratory colony were prepared and directly compared with the published B. dorsalis s.s. map (Zacharopoulou et al. 2011a), the already published B. tryoni map (Zhao et al. 1998) and photos from polytene chromosomes of the five taxa of the dorsalis complex. This analysis 

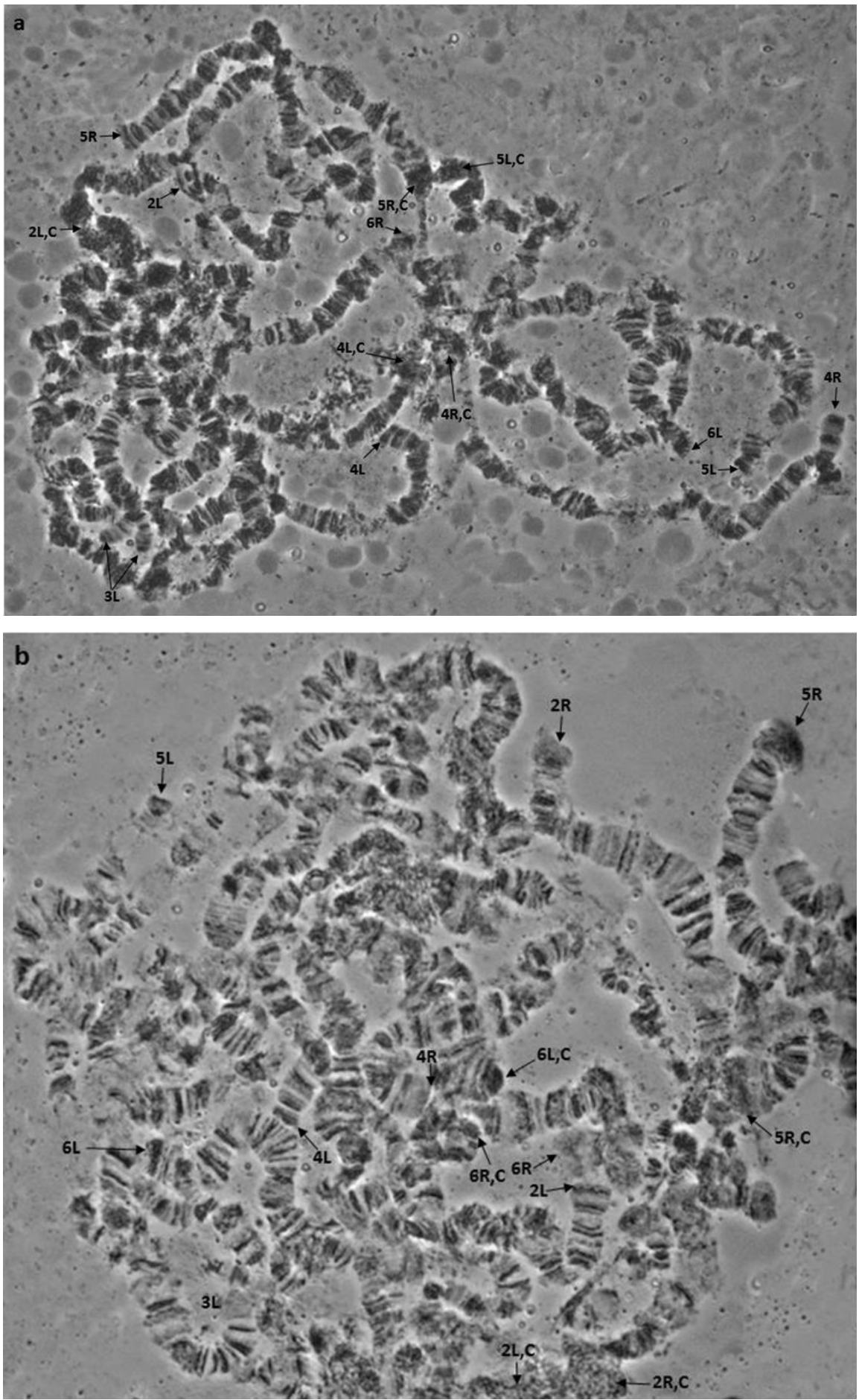

Figure I. a, b Polytene nuclei of $B$. dorsalis s.s. from China. Chromosome arms are shown. Tips are marked with arrows and centromeres are indicated with ' $\mathrm{C}$ '. 

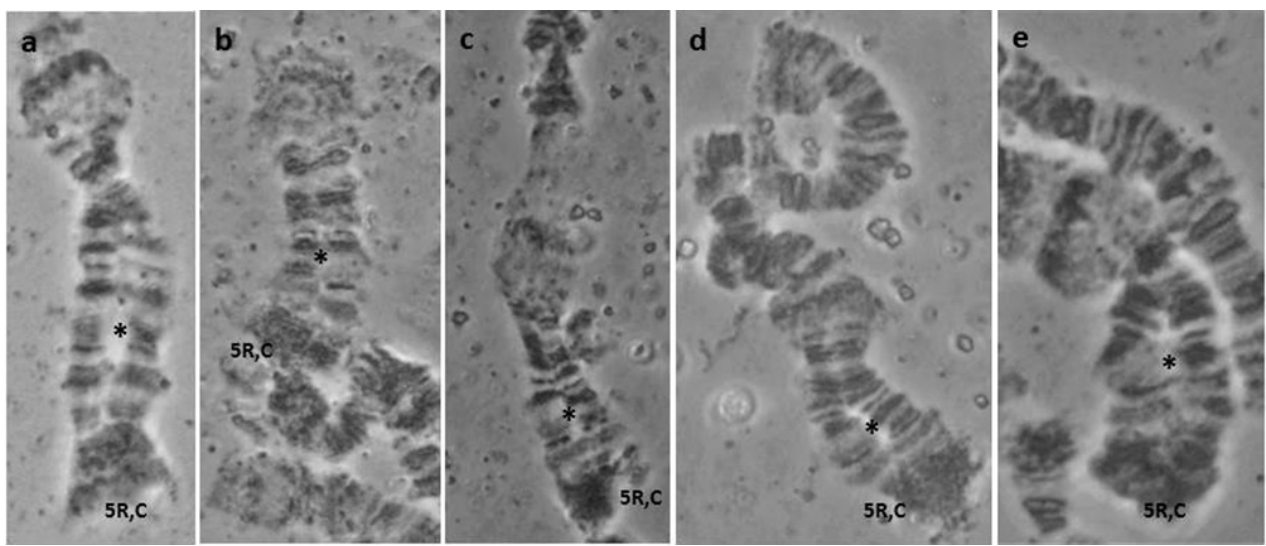

Figure 2. a-e Characteristic asynapsis in $5 \mathrm{R}$ chromosome arm, close to the centromere (regions 73-74), observed in the $B$. dorsalis s.s. colony derived from China. Asterisks $\left(^{*}\right)$ mark the asynaptic region, while ' $\mathrm{C}$ ' marks the $5 \mathrm{R}$ centromere.
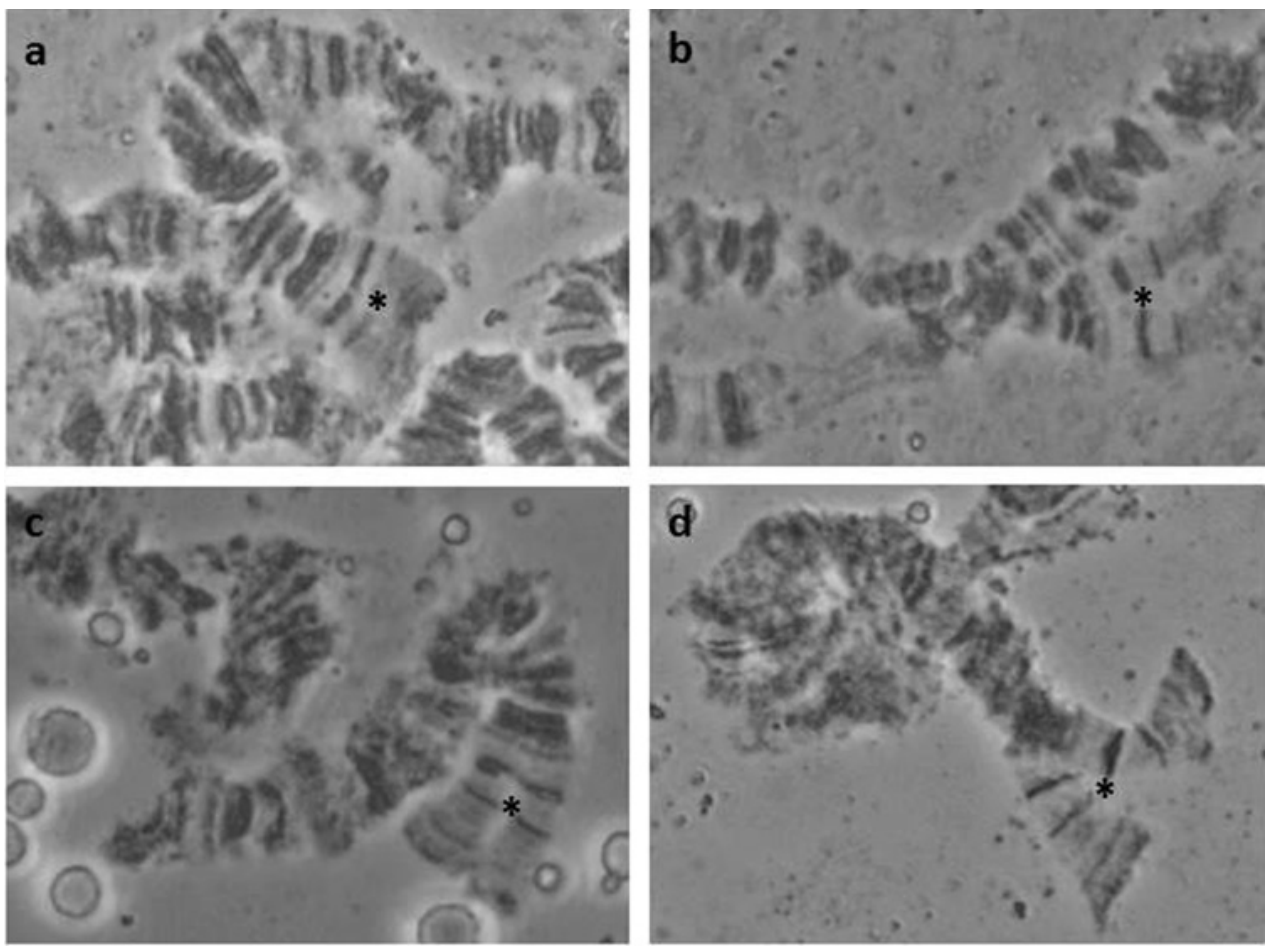

Figure 3. Characteristic asynapsis in the $3 \mathrm{~L}$, close to the tip region, observed in B. dorsalis colony derived from China. a almost completely synapsed region $\mathbf{b}-\mathbf{d}$ asynapses of the same region; asterisks $\left({ }^{*}\right)$ indicate the specific region. 
showed that this colony is homosequential with the previously published map of $B$. tryoni. A comparison between $B$. tryoni and the five dorsalis taxa showed that nine of the ten polytene arms can be regarded as highly homosequential, verifying the genetic proximity between them (Figures 4-6). However, a fixed chromosomal inversion that was previously described (Augustinos et al. 2014b), based on a comparison of polytene chromosome maps of the two species (B. dorsalis s.s. and B. tryoni), was verified in the new polytene chromosome squashes of the IPCL colony (Figure 7). This CR is quite extended, covering a large region of arm $2 \mathrm{R}$.

To further verify the proposed syntenies, a cytogenetic analysis of $\mathrm{F}_{1}$ bidirectional hybrids of B. dorsalis s.s. and B. tryoni was performed. Consistently with the aforementioned conclusions good synapsis can be seen in $9 / 10$ polytene arms, while asynaptic regions are also present, as expected for hybrids of well-differentiated species (Figure 8). The inversion covering a large part of the $2 \mathrm{R}$ chromosome arm (Figure $8 \mathrm{~b}$ ) can also be observed, although its extension usually leads to chromosome breaks that make the mapping of breakpoints rather difficult (Figure 9).

As discussed in the Introduction, CRs are regarded as key players in Diptera speciation. In Tephritidae, all species analysed so far are differentiated by CRs, mainly inversions and transpositions. Focusing on the better studied Tephritidae species $(C$. capitata) and species of two genera that are phylogenetically close to each other (Bactrocera and Dacus), polytene chromosome comparisons performed either in older studies or in the present study have revealed specific CRs that are diagnostic in genus, subgenus and species level. Comparative analysis of the published polytene chromosome maps shows that the pericentric inversion in chromosome 5, firstly described by Zhao et al. (1998), also differentiates C. capitata from the other four Dacus/Bactrocera species studied so far (Zacharopoulou 1990, Mavragani-Tsipidou et al. 1992, Zacharopoulou et al. 2011a, 2011b, Drosopoulou et al. 2011b). Within the Dacus/Bactrocera clade, polytene chromosomes provide evidence for the genetic proximity of Bactrocera Zeugodacus and Bactrocera Daculus (to a lesser extend) with Dacus. More specifically, there are certain CRs shared between B. cucurbitae (Zeugodacus), B. oleae (Daculus) and $D$. ciliatus in contrast to the two species of the Bactrocera subgenus (B. dorsalis s.s. and $B$. tryoni). A characteristic example is a pericentric inversion in chromosome 6 that changes the length ratio of the two arms, clearly evident when comparing the maps of these species (Mavragani-Tsipidou et al. 1992, Zhao et al. 1998, Zacharopoulou et al. 2011a, 2011b, Drosopoulou et al. 2011b). On the other hand, B. oleae shares also some characteristic CRs with the typical Bactrocera (Mavragani-Tsipidou et al. 1992, Zhao et al. 1998, Zacharopoulou et al. 2011a, 2011b, Drosopoulou et al. 2011b). Informative is also chromosome 2 , since its right arm is considered as highly polymorphic among the different Tephritidae species. The region involved in the $2 \mathrm{R}$ inversion described before does not only differentiate $B$. tryoni from the $B$. dorsalis taxa analysed so far. This region has a unique banding pattern and/or position among the five Bactrocera/Dacus species analysed so far (Mavragani-Tsipidou et al. 1992, Zhao et al. 1998, Zacharopoulou et al. 2011a, 2011b, Drosopoulou et al. 2011b). All the above findings are in accordance with recent studies discussing either the genetic proximity 


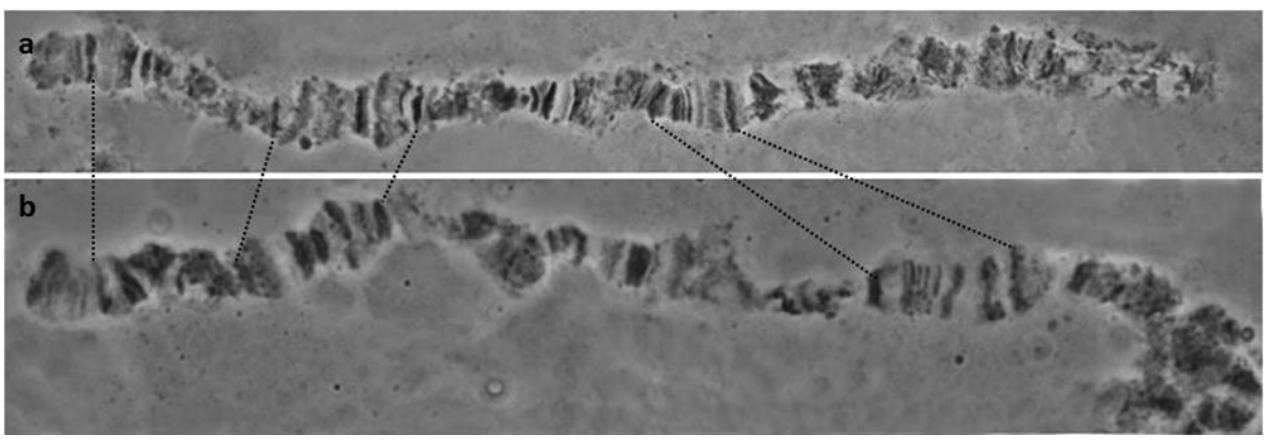

Figure 4. Comparison of the $3 \mathrm{~L}$ polytene chromosome arm of $\mathbf{a} B$. tryoni and $\mathbf{b}$ B. dorsalis s.s. Dot lines connect characteristic landmarks of the two chromosomes.

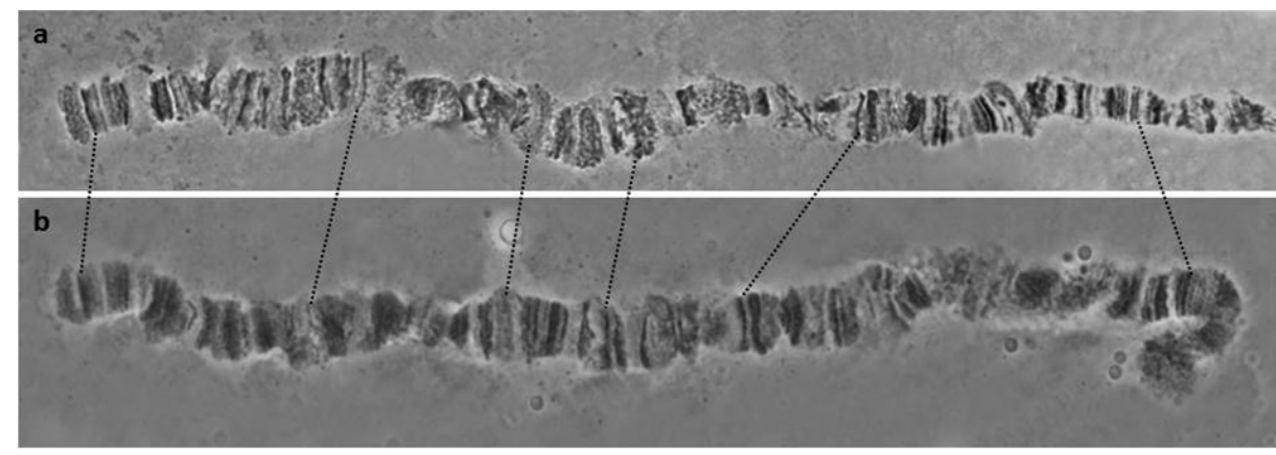

Figure 5. Comparison of the $4 \mathrm{~L}$ polytene chromosome arms of $\mathbf{a}$ B. tryoni and $\mathbf{b}$ B. dorsalis s.s.. Dot lines connect characteristic landmarks of the two chromosomes.

of specific Bactrocera subgenera with Dacus or the actual status of specific subgenera, especially the Zeugodacus subgenus (Virgilio et al. 2009, Krosch et al. 2012, Virgilio et al. 2015).

Taking together that (a) all different Tephritidae species analysed so far exhibit characteristic CRs and (b) no diagnostic CRs could be observed in the five taxa of the $B$. dorsalis complex analysed here, it is clear that polytene chromosome analysis does so far not support a CR-mediated speciation event in the taxa under study.

\section{Reproductive symbiont screening - lack of evidence for symbiotic involvement in speciation events}

The PCR screening for Arsenophonus, Cardinium, Spiroplasma, Rickettsia and Wolbachia did not reveal any signs of infection in the 19 colonies tested (Table 1). However, since this analysis was performed on populations colonized for many generations, this does not necessarily represent the 'actual' symbiotic status of these species in the 

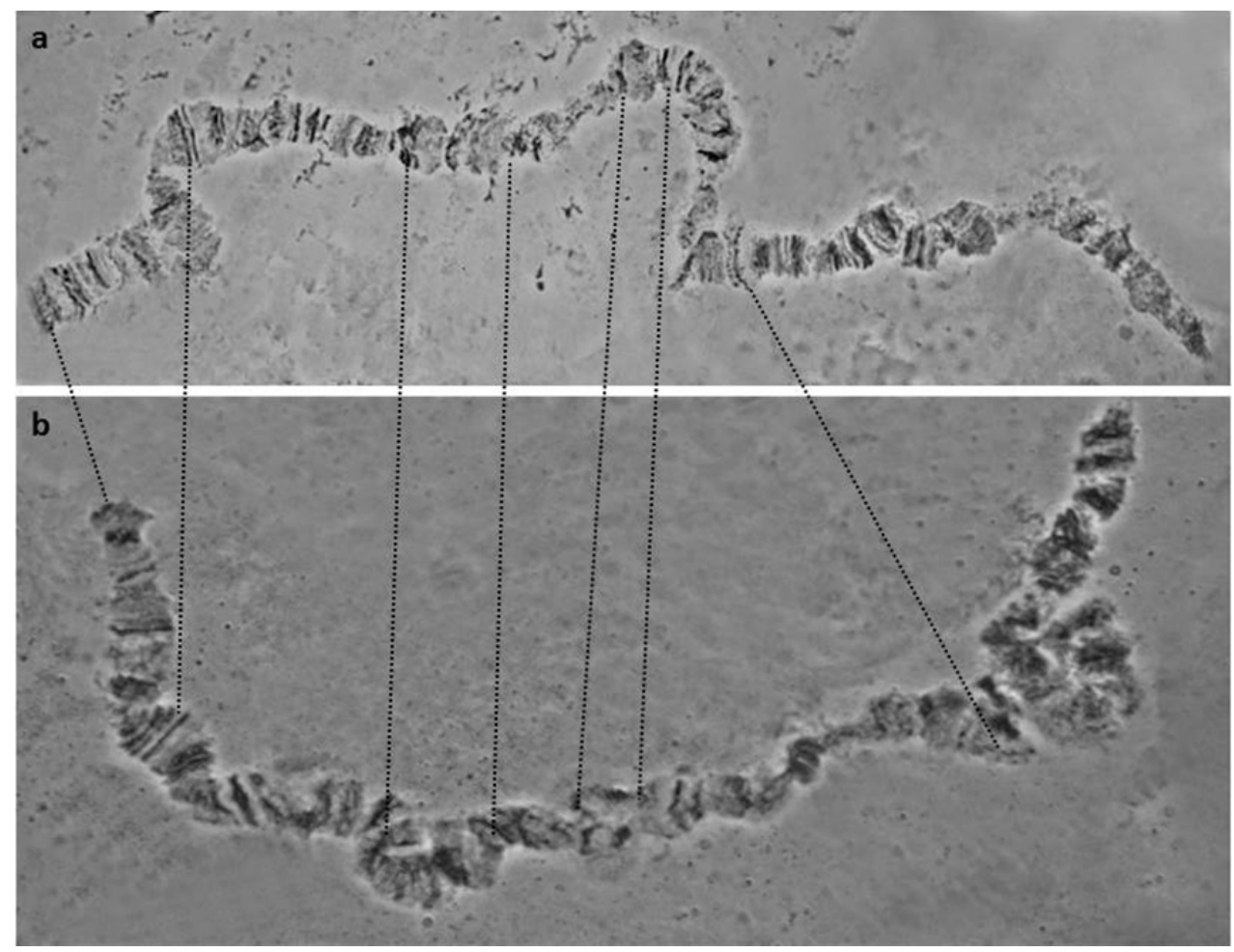

Figure 6. Comparison of the $5 \mathrm{~L}$ polytene chromosome arms of $\mathbf{a}$ B. tryoni and $\mathbf{b} B$. dorsalis s.s. Dot lines connect characteristic landmarks of the two chromosomes.

wild. Colonization might have drastically affected the symbiotic communities of the respective populations. Although there is no evidence for the implication of reproductive symbionts on speciation events between the investigated taxa, symbiotic analysis of wild populations is thus crucial to fully resolve the symbiotic status of these taxa and the dorsalis complex in general.

In Tephritidae, only Wolbachia has so far been found in a limited number of species, while there are no reports of the presence of the other four symbionts. This can partly be attributed to a lack of comprehensive surveys. Regarding the $B$. dorsalis complex, there are reports for the presence of Wolbachia in natural populations (Kittayapong et al. 2000, Jamnongluk et al. 2002, Sun et al. 2007), however only a few populations and at very low frequencies. The first of them (Kittayapong et al. 2000) reports a Wolbachia PCR screening of fruit flies of Thailand, collected in the years 19951998. Screening was based on the fts $Z$ gene and supergroup-typing on wsp sequences. Only 2/222 of the mitotic form A samples and one out of two of the mitotic form K samples were infected. The infection was reported as belonging to supergroup B. Later on, the same research group, using the same samples, suggested the presence of multiple Wolbachia infections (Jamnongluk et al. 2002). More recently, a study performed on Chinese populations of $B$. dorsalis s.s. (Sun et al. 2007) revealed very low levels of 


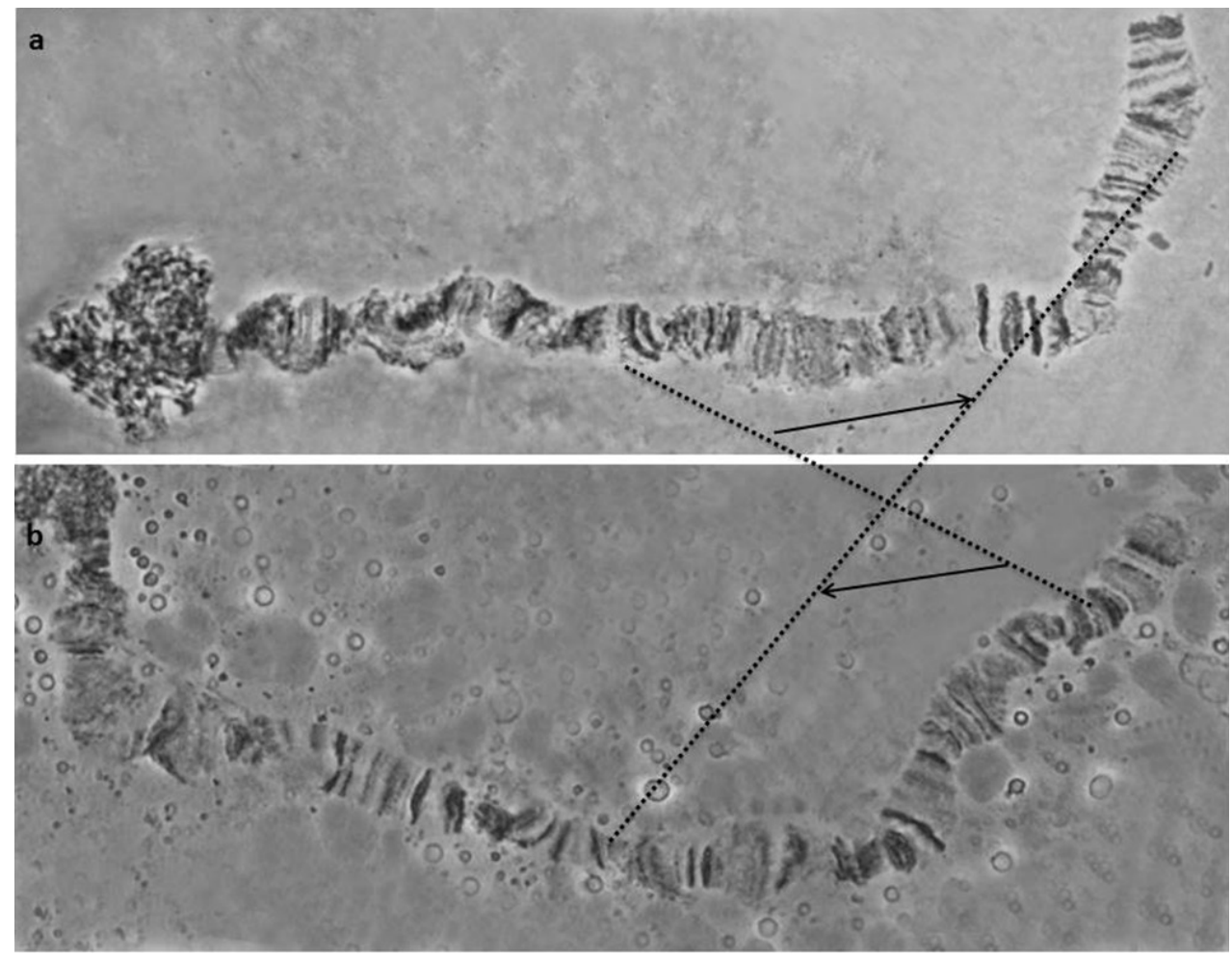

Figure 7. The inverted region on the $2 \mathrm{R}$ polytene arm that differentiates $B$. tryoni from the five members of the $B$. dorsalis complex: a B. tryon $i \mathbf{b}$ B. dorsalis s.s. Dotted lines mark the chromosomal region involved in the inversion while arrows indicate the orientation.

Wolbachia infections (19 positive samples of 1500), belonging either to supergroup A or $\mathrm{B}$, based on $w s p$ sequencing. Given the available knowledge at the time of these screens, the specimens tested might have not been properly identified at the species level. In any case, it is highly unlikely that at such low frequencies Wolbachia infection could trigger or support a speciation event.

\section{Conclusion}

CRs are a well-known indicator of speciation in Diptera, while symbionts obtain only during the last years more recognition as putative speciation factors. Analysing possible paths of speciation with multidisciplinary approaches (integrative taxonomy) is now acknowledged as the best way to provide robust results in species delimitation (De Queiroz 2007, Schlick-Steiner et al. 2010). Our analysis, focused on five economically important members of the $B$. dorsalis complex currently colonized at the Joint FAO/IAEA IPCL, failed to identify any fixed CRs or specific reproductive symbionts that could have partici- 

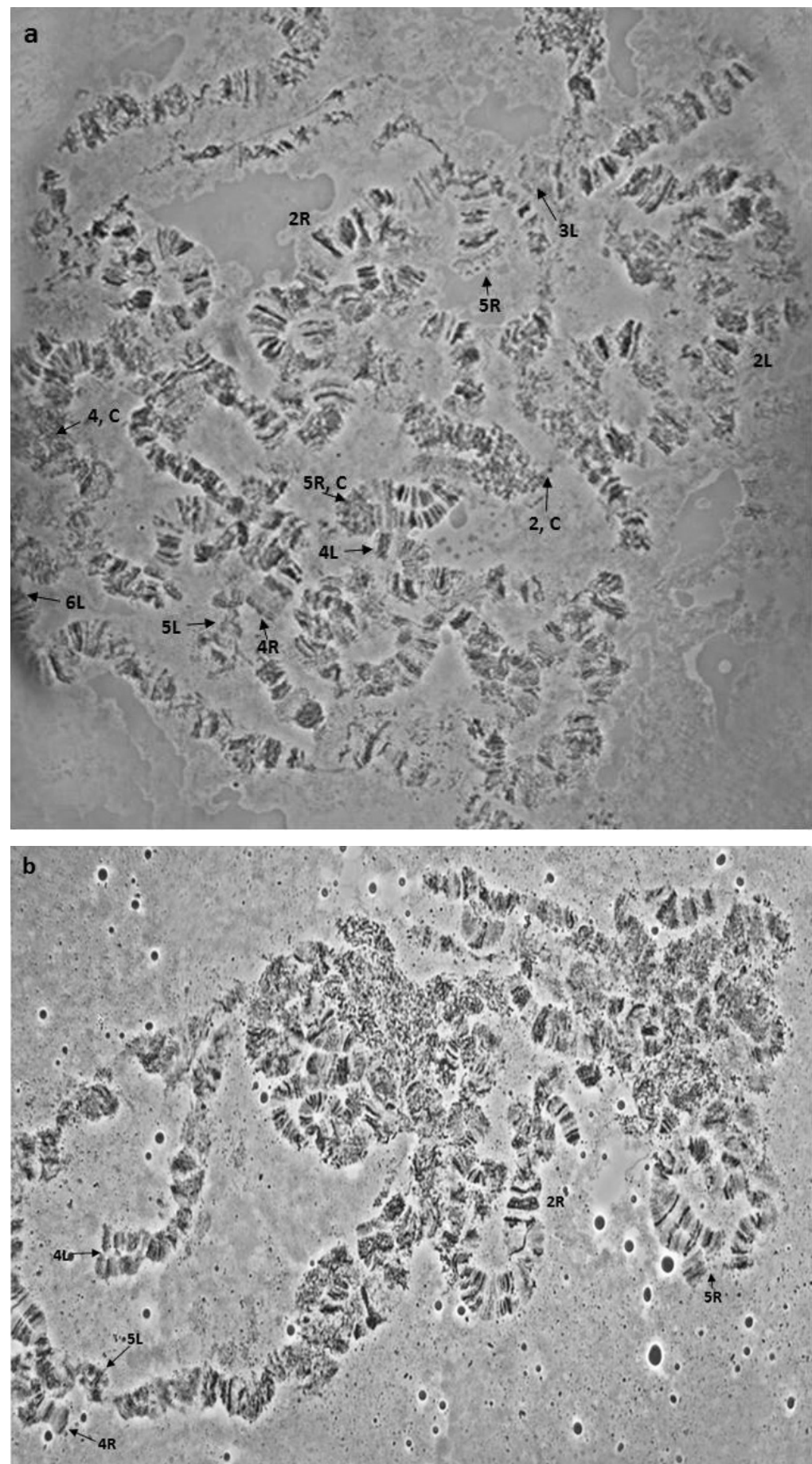

Figure 8. a, b Polytene nuclei derived from the $\mathrm{F}_{1}$ B. dorsalis s.s. $\times$ B. tryoni hybrids. Chromosome arms are indicated. Tips are marked with arrows and centromeres are indicated with ' $C$ '. Note the overall banding pattern homosequentiallity and the presence of limited asynapses. 


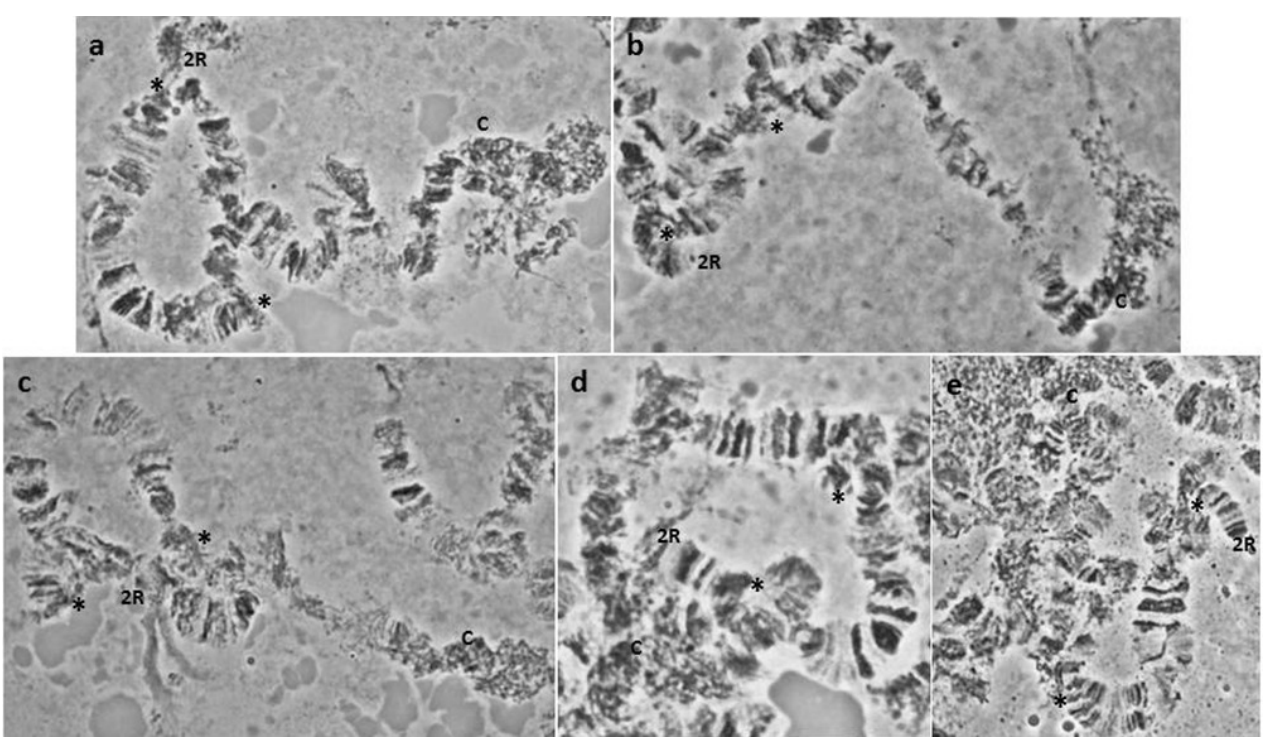

Figure 9. a-e Part of the $2 \mathrm{R}$ chromosome arm including the fixed inversion. Photos derived from different polytene chromosome preparations. Asterisks $\left({ }^{*}\right)$ indicate the inversion breakpoints. ' $\mathrm{C}$ ' indicates the $2 \mathrm{R}$ centromere.

pated in the speciation process in the complex. These results are in line with recent data that question the 'actual' number of species within the B. dorsalis complex (Krosch et al. 2013, Schutze et al. 2013, San Jose et al. 2013, Boykin et al. 2014) and have led to the recent synonymization proposed by Schutze and colleagues (Schutze et al. 2015). Analysis of species within the complex that are more clearly differentiated from the five taxa under study could shed more light on the speciation process within the $B$. dorsalis complex.

\section{Acknowledgements}

The present study has been partially funded by the Joint FAO/IAEA Coordinated Research Project (CRP) 'Resolution of Cryptic Species Complexes of Tephritid Pests to Enhance SIT Application and Facilitate International Trade'. We would also like to thank the three reviewers for their constructive comments.

\section{References}

Arthofer W, Riegler M, Schneider D, Krammer M, Miller WJ, Stauffer C (2009) Hidden Wolbachia diversity in field populations of the European cherry fruit fly, Rhagoletis cerasi (Diptera, Tephritidae). Molecular Ecology 18: 3816-3830. doi: 10.1111/j.1365294X.2009.04321.x 
Ashburner M, Carson HL, Thompson J (1982) The Genetics and Biology of Drosophila. Ashburner M, Carson HL, Thompson J (Eds) Academic press, London.

Augustinos AA, Asimakopoulou AK, Moraiti CA, Mavragani-Tsipidou P, Papadopoulos NT, Bourtzis K (2014a) Microsatellite and Wolbachia analysis in Rhagoletis cerasi natural populations: population structuring and multiple infections. Ecology and Evolution 4: 1943-1962. doi: $10.1002 /$ ece 3.553

Augustinos AA, Drosopoulou E, Gariou-Papalexiou A, Bourtzis K, Mavragani-Tsipidou P, Zacharopoulou A (2014b) The Bactrocera dorsalis species complex: comparative cytogenetic analysis in support of Sterile Insect Technique applications. BMC Genetics 15 Suppl 2: S16. doi: 10.1186/1471-2156-15-S2-S16

Baimai V (1998) Heterochromatin accumulation and karyotypic evolution in some dipteran insects. Zoological Studies 37: 75-88.

Baimai V (2000) Cytological evidence for a complex of species within the taxon Bactrocera tau (Diptera: Tephritidae) in Thailand. Biological Journal of the Linnean Society 69: 399-409. doi: 10.1006/bijl.1999.0377

Baimai V, Phinchongsakuldit J, Tigvattananont S (1999) Metaphase karyotypes of fruit flies of Thailand. IV. Evidence for six new species of the Bactrocera dorsalis complex. Cytologia 64: 371-377. doi: 10.1508/cytologia.64.371

Baimai V, Sumrandee C, Tigvattananont S, Trinachartvanit W (2000) Metaphase karyotypes of fruit flies of Thailand. V. Cytotaxonomy of ten additional new species of the Bactrocera dorsalis complex. Cytologia 65: 409-417. doi: 10.1508/cytologia.65.409

Baimai V, Trinachartvanit W, Tigvattananont S, Grote PJ, Poramarcom R, Kijchalao U (1995) Metaphase karyotypes of fruit flies of Thailand. I. Five sibling species of the Bactrocera dorsalis complex. Genome 38: 1015-1022. doi: 10.1139/g95-134

Bhutkar A, Schaeffer SW, Russo SM, Xu M, Smith TE, Gelbart WM (2008) Chromosomal rearrangement inferred from comparisons of 12 Drosophila genomes. Genetics 179: 1657-1680. doi: 10.1534/genetics.107.086108

Bo W, Ahmad S, Dammalage T, Tomas US, Wornoayporn V, Ul Haq I, Cáceres C, Vreysen MJB, Hendrichs J, Schutze MK (2014) Mating compatibility between Bactrocera invadens and Bactrocera dorsalis (Diptera: Tephritidae). Journal of Economic Entomology 107: 623-629. doi: 10.1603/EC13514

Bordenstein SR, O'Hara FP, Werren JH (2001) Wolbachia-induced incompatibility precedes other hybrid incompatibilities in Nasonia. Nature 409: 707-710. doi: 10.1038/35055543

Bordenstein SR, Werren JH (2007) Bidirectional incompatibility among divergent Wolbachia and incompatibility level differences among closely related Wolbachia in Nasonia. Heredity 99: 278-287. doi: 10.1038/sj.hdy.6800994

Bourtzis K, Miller T (Eds) (2003) Insect Symbiosis. CRC Press, Taylor and Francis Group, LLC, Florida, USA. doi: 10.1201/9780203009918

Bourtzis K, Miller T (Eds) (2006) Insect Symbiosis 2. CRC Press, Taylor and Francis Group, LLC, Florida, USA.

Bourtzis K, Miller T (Eds) (2009) Insect Symbiosis 3. CRC Press, Taylor and Francis Group, LLC, Florida, USA. 
Bourtzis K, Nirgianaki A, Onyango P, Savakis C (1994) A prokaryotic dnaA sequence in Drosophila melanogaster: Wolbachia infection and cytoplasmic incompatibility among laboratory strains. Insect Molecular Biology 3: 131-142. doi: 10.1111/j.1365-2583.1994.tb00160.x

Boykin LM, Schutze MK, Krosch MN, Chomič A, Chapman TA, Englezou A, Armstrong KF, Clarke AR, Hailstones D, Cameron SL (2014) Multi-gene phylogenetic analysis of southeast Asian pest members of the Bactrocera dorsalis species complex (Diptera: Tephritidae) does not support current taxonomy. Journal of Applied Entomology 138: 235-253. doi: $10.1111 /$ jen. 12047

Bush GL, Boller E (1977) The chromosome morphology of the Rhagoletis cerasi species complex (Diptera, Tephritidae). Annals of the Entomological Society of America 70: 316-318. doi: 10.1093/aesa/70.3.316

Cáceres C, Segura DF, Vera MT, Wornoayporn V, Cladera JL, Teal P, Sapountzis P, Bourtzis K, Zacharopoulou A, Robinson AS (2009) Incipient speciation revealed in Anastrepha fraterculus (Diptera; Tephritidae) by studies on mating compatibility, sex pheromones, hybridization, and cytology. Biological Journal of the Linnean Society 97: 152-165. doi: 10.1111/j.1095-8312.2008.01193.x

Cevallos VE, Nation JL (2004) Chromosomes of the Caribbean fruit fly (Diptera: Tephritidae). Florida Entomologist 87: 361-364. doi: 10.1653/0015-4040(2004)087[0361:COT $\mathrm{CFF}] 2.0 . \mathrm{CO} ; 2$

Coats VC, Stack PA, Rumpho ME (2013) Japanese barberry seed predation by Rhagoletis meigenii fruit flies harboring Wolbachia endosymbionts. Symbiosis 59: 145-156. doi: 10.1007/s13199-013-0223-5

Coscrato VE, Braz ASK, Perondini AL, Selivon D, Marino CL (2009) Wolbachia in Anastrepha fruit flies (Diptera: Tephritidae). Current Microbiology 59: 295-301. doi: 10.1007/ s00284-009-9433-8

Doyle JJ, Doyle JL (1990) Isolation of plant DNA from fresh tissue. Focus 12: 13-15.

Drew RAI, Hancock DL (1994) The Bactrocera dorsalis complex of fruit flies (Diptera: Tephritidae: Dacinae) in Asia. Bulletin of Entomological Research Suppl. 2: 1-69. doi: 10.1017/ S1367426900000278

Drew, Romig M (2013) Tropical Fruit Flies of South-East Asia (Tephritidae: Dacinae). CABI, Wallingford, Oxfordshire.

Drosopoulou E, Augustinos AA, Nakou I, Koeppler K, Kounatidis I, Vogt H, Papadopoulos NT, Bourtzis K, Mavragani-Tsipidou P (2011a) Genetic and cytogenetic analysis of the American cherry fruit fly, Rhagoletis cingulata (Diptera: Tephritidae). Genetica 139: 1449-1464. doi: 10.1007/s10709-012-9644-y

Drosopoulou E, Koeppler K, Kounatidis I, Nakou I, Papadopoulos NT, Bourtzis K, Mavragani-Tsipidou P (2010) Genetic and cytogenetic cnalysis of the Walnut-Husk Fly (Diptera: Tephritidae). Annals of the Entomological Society of America 103: 1003-1011. doi: 10.1603/AN10059

Drosopoulou E, Nakou I, Sichova J, Kubíčková S, Marec F, Mavragani-Tsipidou P (2012) Sex chromosomes and associated rDNA form a heterochromatic network in the polytene nuclei of Bactrocera oleae (Diptera: Tephritidae). Genetica 140: 169-180. doi: 10.1007/ s10709-012-9668-3 
Drosopoulou E, Nestel D, Nakou I, Kounatidis I, Papadopoulos NT, Bourtzis K, MavraganiTsipidou P (2011b) Cytogenetic analysis of the Ethiopian fruit fly Dacus ciliatus (Diptera: Tephritidae). Genetica 139: 723-732. doi: 10.1007/s10709-011-9575-z

Duron O, Bouchon D, Boutin S, Bellamy L, Zhou L, Engelstädter J, Hurst GD (2008a) The diversity of reproductive parasites among arthropods: Wolbachia do not walk alone. BMC Biology 6: 27. doi: 10.1186/1741-7007-6-27

Duron O, Hurst GDD, Hornett EA, Josling JA, Engelstädter J (2008b) High incidence of the maternally inherited bacterium Cardinium in spiders. Molecular Ecology 17: 1427-1437. doi: 10.1111/j.1365-294X.2008.03689.x

Faria R, Navarro A (2010) Chromosomal speciation revisited: rearranging theory with pieces of evidence. Trends in Ecology and Evolution 25: 660-669. doi: 10.1016/j.tree.2010.07.008

Flor M, Hammerstein P, Telschow A (2007) Wolbachia-induced unidirectional cytoplasmic incompatibility and the stability of infection polymorphism in parapatric host populations. Journal of Evolutionary Biology 20: 696-706. doi: 10.1111/j.1420-9101.2006.01252.x

Fukatsu T, Nikoh N (2000) Endosymbiotic microbiota of the bamboo pseudococcid Antonina crawii (Insecta, Homoptera). Applied and Environmental Microbiology 66: 643-650. doi: 10.1128/AEM.66.2.643-650.2000

Garcia-Martinez V, Hernández-Ortiz E, Zepeta-Cisneros CS, Robinson AS, Zacharopoulou A, Franz G (2009) Mitotic and polytene chromosome analysis in the Mexican fruit fly, Anastrepha ludens (Loew) (Diptera: Tephritidae). Genome 52: 20-30. doi: 10.1139/G08-099

Gilchrist AS, Cameron EC, Sved JA, Meats AW (2012) Genetic consequences of domestication and mass rearing of pest fruit fly Bactrocera tryoni (Diptera: Tephritidae). Journal of Economic Entomology 136: 252-262. doi: 10.1603/ec11421

Goday C, Selivon D, Perondini ALP, Greciano PG, Ruiz MF (2006) Cytological characterization of sex chromosomes and ribosomal DNA location in Anastrepha species (Diptera, Tephritidae). Cytogenetic and Genome Research 114: 70-76. doi: 10.1159/000091931

Gotoh T, Noda H, Ito S (2007) Cardinium symbionts cause cytoplasmic incompatibility in spider mites. Heredity 98: 13-20. doi: 10.1038/sj.hdy.6800881

Hanner R, Fugate M (1997) Branchiopod phylogenetic reconstruction from 12S rDNA sequence data. Journal of Crustacean Biology 17: 174-183. doi: 10.2307/1549471

Hilgenboecker K, Hammerstein P, Schlattmann P, Telschow A, Werren JH (2008) How many species are infected with Wolbachia? A statistical analysis of current data. FEMS Microbiology Letters 281: 215-220. doi: 10.1111/j.1574-6968.2008.01110.x

Hunwattanakul N, Baimai V (1994) Mitotic karyotypes of four species of fruit flies (Bactrocera) in Thailand. Kasetsart J. (nat.Sci.) 28: 142-148.

Jaenike J, Dyer KA, Cornish C, Minhas MS (2006) Asymmetrical reinforcement and Wolbachia infection in Drosophila. PLoS Biology 4: e325. doi: 10.1371/journal.pbio.0040325

Jamnongluk W, Kittayapong P, Baimai V, O’Neill SL (2002) Wolbachia infections of tephritid fruit flies: Molecular evidence for five distinct strains in a single host species. Current Microbiology 45: 255-260. doi: 10.1007/s00284-002-3746-1

Karimi J, Darsouei R (2014) Presence of the endosymbiont Wolbachia among some fruit flies (Diptera: Tephritidae) from Iran: A multilocus sequence typing approach. Journal of AsiaPacific Entomology 17: 105-112. doi: 10.1016/j.aspen.2013.11.002 
Kirkpatrick M, Barton N (2006) Chromosome inversions, local adaptation and speciation. Genetics 173: 419-434. doi: 10.1534/genetics.105.047985

Kittayapong P, Milne JR, Tigvattananont S, Baimai V (2000) Distribution of the reproduction-modifying bacteria, Wolbachia, in natural populations of tephritid fruit flies in Thailand. Sci. Asia 26: 93-103. doi: 10.2306/scienceasia1513-1874.2000.26.093

Koukou K, Pavlikaki H, Kilias G, Werren JH, Bourtzis K, Alahiotis SN (2006) Influence of antibiotic treatment and Wolbachia curing on sexual isolation among Drosophila melanogaster cage populations. Evolution 60: 87. doi: 10.1554/05-374.1

Kounatidis I, Papadopoulos N, Bourtzis K, Mavragani-Tsipidou P (2008) Genetic and cytogenetic analysis of the fruit fly Rhagoletis cerasi (Diptera: Tephritidae). Genome 51: 479-491. doi: 10.1139/G08-032

Krimbas CB, Powell JR (1992) Drosophila inversion polymorphism. In: Krimbas CB, Powell JR (Eds) CRC Press, Inc, USA.

Krosch MN, Schutze MK, Armstrong KF, Graham GC, Yeates DK, Clarke AR (2012) A molecular phylogeny for the Tribe Dacini (Diptera: Tephritidae): systematic and biogeographic implications. Molecular Phylogenetics and Evolution 64: 513-523. doi: 10.1016/j. ympev.2012.05.006

Krosch MN, Schutze MK, Armstrong KF, Boontop Y, Boykin LM, Chapman TA, Englezou A, Cameron SL, Clarke AR (2013) Piecing together an integrative taxonomic puzzle: Microsatellite, wing shape and aedeagus length analyses of Bactrocera dorsalis s.l. (Diptera: Tephritidae) find no evidence of multiple lineages in a proposed contact zone along the Thai/Malay Peninsul. Systematic Entomology: 38: 2-13. doi: 10.1111/j.1365-3113.2012.00643.x

Kulathinal RJ, Stevison LS, Noor MAF (2009) The genomics of speciation in Drosophila: Diversity, divergence, and introgression estimated using low-coverage genome sequencing. Plos Genetics 5. doi: 10.1371/journal.pgen.1000550

Lee Y, Collier TC, Sanford MR, Marsden CD, Fofana A, Cornel AJ, Lanzaro GC (2013) Chromosome inversions, genomic differentiation and speciation in the african malaria mosquito Anopheles gambiae. PLoS ONE 8. doi: 10.1371/journal.pone.0057887

Marcon HS, Coscrato VE, Selivon D, Perondini ALP, Marino CL (2011) Variations in the sensitivity of different primers for detecting Wolbachia in Anastrepha (Diptera: Tephritidae). Brazilian Journal of Microbiology 42: 778-785. doi: 10.1590/S151783822011000200046

Martinez H, Toledo J, Liedo P, Mateos M (2012) Survey of heritable endosymbionts in southern Mexico populations of the fruit fly species Anastrepha striata and A. ludens. Current Microbiology 65: 711-718. doi: 10.1007/s00284-012-0223-3

Mateos M, Castrezana SJ, Nankivell BJ, Estes AM, Markow TA, Moran NA (2006) Heritable endosymbionts of Drosophila. Genetics 174: 363-376. doi: 10.1534/genetics.106.058818

Mavragani-Tsipidou P, Karamanlidou G, Zacharopoulou A, Koliais S, Kastritsis C (1992) Mitotic and polytene chromosome analysis in Dacus oleae (Diptera: Tephritidae). Genome 35: 373-378. doi: 10.1139/g92-056

Mavragani-Tsipidou P, Zacharopoulou A, Drosopoulou E, Augustinos AA, Bourtzis K, Marec F (2014) Protocols for cytogenetic mapping of insect genomes. Tephritid Fruit Flies. In: Sarakov I (Ed.) CRC Press, Taylor and Francis Group, LLC, 62 pp. 
McGaugh SE, Noor MAF (2012) Genomic impacts of chromosomal inversions in parapatric Drosophila species. Philosophical Transactions of the Royal Society B-Biological Sciences 367: 422-429. doi: 10.1098/rstb.2011.0250

Miller WJ, Ehrman L, Schneider D (2010) Infectious speciation revisited: impact of symbiontdepletion on female fitness and mating behavior of Drosophila paulistorum. PLoS Pathogens 6: e1001214. doi: 10.1371/journal.ppat.1001214

Morrow JL, Frommer M, Shearman DCA, Riegler M (2015) The microbiome of field-caught and laboratory adapted australian tephritid fruit fly species with different host plant use and specilisation. Microbial Ecology 70(2): 498-508. doi: 10.1007/s00248-015-0571-1

Noor MAF, Grams KL, Bertucci LA, Reiland J (2001) Chromosomal inversions and the reproductive isolation of species. Proceedings of the National Academy of Sciences of the United States of America 98: 12084-12088. doi: 10.1073/pnas.221274498

Parreńo MA, Scannapieco AC, Remis MI, Juri M, Vera MT, Segura DF, Cladera JL, Lanvavecchia SB (2014) Dynamics of genetic variabillity in Anastrepha fraterculus (Diptera: Tephritidae) during adaptation to laboratory rearing conditions. BMC Genetics 15: S14. http://www.biomedcentral.com/1471-2156/15/S2/S14

Perlman SJ, Hunter MS, Zchori-Fein E (2006) The emerging diversity of Rickettsia. Proceedings of the Royal Society B: Biological sciences 273: 2097-2106. doi: 10.1098/rspb.2006.354

De Queiroz K (2007) Species concepts and species delimitation. Systematic Biology 56: 879-886. doi: 10.1080/10635150701701083

Ranz JM, Maurin D, Chan YS, von Grotthuss M, Hillier LW, Roote J, Ashburner M, Bergman CM (2007) Principles of genome evolution in the Drosophila melanogaster species group. PLoS Biology 5: 1366-1381. doi: 10.1371/journal.pbio.0050152

Riegler M, Stauffer C (2002) Wolbachia infections and superinfections in cytoplasmically incompatible populations of the European cherry fruit fly Rhagoletis cerasi (Diptera, Tephritidae). Molecular Ecology 11: 2425-2434. doi: 10.1046/j.1365-294X.2002.01614.x

Rieseberg LH (2001) Chromosomal rearrangements and speciation. Trends in Ecology and Evolution 16: 351-358. doi: 10.1016/S0169-5347(01)02187-5

Rocha LS, Mascarenhas RO, Perondini ALP, Selivon D (2005) Occurunce of Wolbachia in Brazilian samples of Ceratitis capitata (Wiedemann) (Diptera: Tephritidae). Neotropical Entomology 34: 1013-1015. doi: 10.1590/S1519-566X2005000600020

San Jose M, Leblanc L, Geib SM, Rubinoff D (2013) An Evaluation of the Species Status of Bactrocera invadens and the Systematics of the Bactrocera dorsalis (Diptera: Tephritidae) Complex. Annals of the Entomological Society of America 106: 684-694. doi: 10.1603/AN13017

Saridaki A, Bourtzis K (2010) Wolbachia: more than just a bug in insects genitals. Current Opinion in Microbiology 13: 67-72. doi: 10.1016/j.mib.2009.11.005

Schaeffer SW, Bhutkar AU, McAllister BF, Matsuda M, Matzkin LM, O’Grady PM, Rohde C, Valente VLS, Aguade M, Anderson WW, Edwards K, Garcia ACL, Goodman J, Hartigan J, Kataoka E, Lapoint RT, Lozovsky ER, Machado CA, Noor MAF, Papaceit M, Reed LK, Richards S, Rieger TT, Russo SM, Sato H, Segarra C, Smith DR, Smith TF, Strelets V, Tobari YN, Tomimura Y, Wasserman M, Watts T, Wilson R, Yoshida K, Markow TA, Gelbartt WM, Kaufman TC (2008) Polytene chromosomal maps of 11 Drosophila species: 
The order of genomic scaffolds inferred from genetic and physical maps. Genetics 179: 1601-1655. doi: 10.1534/genetics.107.086074

Schlick-Steiner BC, Steiner FM, Seifert B, Stauffer C, Christian E, Crozier RH (2010) Integrative taxonomy: a multisource approach to exploring biodiversity. Annual Review of Entomology 55: 421-438. doi: 10.1146/annurev-ento-112408-085432

Schuler H, Arthofer W, Riegler M, Bertheau C, Krumböck S, Köppler K, Vogt H, Teixeira LAF, Stauffer C (2011) Multiple Wolbachia infections in Rhagoletis pomonella. Entomologia Experimentalis et Applicata 139: 138-144. doi: 10.1111/j.1570-7458.2011.01115.x

Schuler H, Bertheau C, Egan SP, Feder JL, Riegler M, Schlick-Steiner BC, Steiner FM, Johannesen J, Kern P, Tuba K, Lakatos F, Köppler K, Arthofer W, Stauffer C (2013) Evidence for a recent horizontal transmission and spatial spread of Wolbachia from endemic Rhagoletis cerasi (Diptera: Tephritidae) to invasive Rhagoletis cingulata in Europe. Molecular Ecology 22: 4101-4111. doi: 10.1111/mec.12362

Schutze MK, Aketarawong N, Amornsak W, Armstrong KF, Augustinos AA, Barr N, Bo W, Bourtzis K, Boykin LM, Cáceres C, Cameron SL, Chapman TA, Chinvinijkul S, Chomič A, De Meyer M, Drosopoulou E, Englezou A, Ekesi S, Gariou-Papalexiou A, Geib SM, Hailstones D, Hasanuzzaman M, Haymer D, Hee AKW, Hendrichs J, Jessup A, Ji Q, Khamis FM, Krosch MN, Leblanc L, Mahmood K, Malacrida AR, Mavragani-Tsipidou P, Mwatawala M, Nishida R, Ono H, Reyes J, Rubinoff D, San Jose M, Shelly TE, Srikachar S, Tan KH, Thanaphum S, Haq I, Vijaysegaran S, Wee SL, Yesmin F, Zacharopoulou A, Clarke AR (2015) Synonymization of key pest species within the Bactrocera dorsalis species complex (Diptera: Tephritidae): taxonomic changes based on a review of 20 years of integrative morphological, molecular, cytogenetic, behavioural and chemoecological data. Systematic Entomology 40: 456-471. doi: $10.1111 /$ syen. 12113

Schutze MK, Jessup A, Ul-Haq I, Vreysen MJB, Wornoayporn V, Vera MT, Clarke AR (2013) Mating compatibility among four pest members of the Bactrocera dorsalis fruit fly species complex (Diptera: Tephritidae). Journal of Economic Entomology 106: 695-707. doi: 10.1603/EC12409

Schutze MK, Krosch MN, Armstrong KF, Chapman TA, Englezou A, Chomič A, Cameron SL, Hailstones D, Clarke AR (2012) Population structure of Bactrocera dorsalis s.s., $B$. papayae and B. philippinensis (Diptera: Tephritidae) in southeast Asia: evidence for a single species hypothesis using mitochondrial DNA and wing-shape data. BMC Evolutionary Biology 12: 130. doi: 10.1186/1471-2148-12-130

Selivon D, Perondini ALP, Ribeiro AF, Marino CL, Lima MMA, Coscrato VE (2002) Wolbachia endosymbiont in a species of the Anastrepha fraterculus complex (Diptera: Tephritidae). Invertebrate Reproduction \& Development 42: 121-127. doi: 10.1080/07924259.2002.9652768

Selivon D, Perondini ALP, Morgante JS (2005) A genetic - morphological characterization of two cryptic species of the Anastrepha fraterculus complex (Diptera: Tephritidae). Annals of the Entomological Society of America 98:367-381. doi: 10.1603/0013-8746(2005)098[0367:AGCOTC]2.0.CO;2 
Selivon D, Sipula FM, Rocha LS, Perondini ALP (2007) Karyotype relationships among Anastrepha bistrigata, A. striata and A. serpentina (Diptera, Tephritidae). Genetics and Molecular Biology 30: 1082-1088. doi: 10.1590/S1415-47572007000600009

Stevison LS, Hoehn KB, Noor MAF (2011) Effects of inversions on within- and betweenspecies recombination and divergence. Genome Biology and Evolution 3: 830-841. doi: 10.1093/gbe/evr081

Sturtevant AH, Dobzhansky T (1936) Inversions in the third chromosome of wild race of Drosophila pseudoobscura, and their use in the study of the history of the species. Proceedings of the National Academy of Sciences of the United States of America 22: 448. doi: 10.1073/pnas.22.7.448

Sun X, Cui L, Li Z (2007) Diversity and phylogeny of Wolbachia infecting Bactrocera dorsalis (Diptera: Tephritidae) populations from China. Environmental Entomology 36: 1283-1289. doi: 10.1603/0046-225X(2007)36[1283:DAPOWI]2.0.CO;2

Tan KH, Wee SL, Ono H, Nishida R (2013) Comparison of methyl eugenol metabolites, mitochondrial COI, and rDNA sequences of Bactrocera philippinensis (Diptera: Tephritidae) with those of three other major pest species within the Dorsalis complex. Applied Entomology and Zoology 48: 275-282. doi: 10.1007/s13355-013-0183-5

Telschow A, Flor M, Kobayashi Y, Hammerstein P, Werren JH (2007) Wolbachia-induced unidirectional cytoplasmic incompatibility and speciation: mainland-island model. PLoS ONE 2: e701. doi: 10.1371/journal.pone.0000701

Telschow A, Hilgenboecker K, Hammerstein P, Werren JH (2014) Dobzhansky-Muller and Wolbachia-induced incompatibilities in a diploid genetic system. PLoS ONE 9: e95488. doi: 10.1371/journal.pone.0095488

Vera MT, Cáceres CE, Wornoayporn V, Islam A, Robinson AS, de La Vega MH, Hendrichs J, Cayol J-P (2006) Mating incompatibility among populations of the South American fruit fly Anastrepha fraterculus (Diptera: Tephritidae). Annals of the Entomological Society of America 99: 387-397. doi: 10.1603/0013-8746(2006)099[0387:MIAPOT]2.0.CO;2

Virgilio M, Jordaens K, Verwimp C, White IM, De Meyer M (2015) Higher phylogeny of frugivorous flies (Diptera, Tephritidae, Dacini): Localised partition conflicts and a novel generic classification. Molecular Phylogenetics and Evolution. doi: 10.1016/j. ympev.2015.01.007

Virgilio M, De Meyer M, White IM, Backeljau T (2009) African Dacus (Diptera: Tephritidae: Molecular data and host plant associations do not corroborate morphology based classifications. Molecular Phylogenetics and Evolution 51: 531-539. doi: 10.1016/j. ympev.2009.01.003

Wee SL, Hee AKW, Tan KH (2002) Comparative sensitivity to and consumption of methyl eugenol in three Bactrocera dorsalis (Diptera: Tephritidae) complex sibling species. Chemoecology 12: 193-197. doi: 10.1007/PL00012668

Werren JH, Baldo L, Clark ME (2008) Wolbachia: master manipulators of invertebrate biology. Nature Reviews. Microbiology 6: 741-51. doi: 10.1038/nrmicro1969

Werren JH, Windsor DM (2000) Wolbachia infection frequencies in insects: Evidence of a global equilibrium? Proceedings of the Royal Society B: Biological Sciences 267: 1277-1285. doi: $10.1098 /$ rspb.2000.1139 
Yesmin F, Clyde MM (2012) Identification and characterization of polytene chromosomes of Bactrocera papayae (Diptera: Tephritidae). Malaysian Applied Biology 41: 11-18.

Zabalou S, Charlat S, Nirgianaki A, Lachaise D, Merçot H, Bourtzis K (2004) Natural Wolbachia infections in the Drosophila yakuba species complex do not induce cytoplasmic incompatibility but fully rescue the $w$ Ri modification. Genetics 167: 827-834. doi: 10.1534/ genetics.103.015990

Zacharopoulou A (1990) Polytene chromosome maps in the medfly Ceratitis capitata. Genome 33: 184-197.

Zacharopoulou A, Augustinos AA, Sayed WAA, Robinson AS, Franz G (2011a) Mitotic and polytene chromosomes analysis of the oriental fruit fly, Bactrocera dorsalis (Hendel) (Diptera: Tephritidae). Genetica 139: 79-90. doi: 10.1007/s10709-010-9495-3

Zacharopoulou A, Franz G (2013) Genetic and cytogenetic characterization of Genetic Sexing Strains of Bactrocera dorsalis and Bactrocera cucurbitae (Diptera: Tephritidae). Journal of Economic Entomology 106: 995-1003. doi: 10.1603/EC12379

Zacharopoulou A, Sayed WAA, Augustinos AA, Yesmin F, Robinson AS, Franz G (2011b) Analysis of mitotic and polytene chromosomes and photographic polytene chromosome maps in Bactrocera cucurbitae (Diptera: Tephritidae). Annals of the Entomological Society of America 104: 306-318. doi: 10.1603/AN10113

Zchori-Fein E, Bourtzis K (Eds) (2011) Manipulative Tenants: Bacteria associated with Arthropods (a volume in the Frontiers in Microbiology Series). CRC Press, Taylor and Francis Group, LLC, Florida, USA.

Zhao JT, Frommer M, Sved JA, Zacharopoulou A (1998) Mitotic and polytene chromosome analyses in the Queensland fruit fly, Bactrocera tryoni (Diptera: Tephritidae). Genome 41: 510-526. doi: 10.1139/gen-41-4-510

Zug R, Hammerstein P (2012) Still a host of hosts for Wolbachia: analysis of recent data suggests that $40 \%$ of terrestrial arthropod species are infected. PLoS ONE 7: e38544. doi: 10.1371/journal.pone.0038544

Zygouridis NE, Argov Y, Nemny-Lavy E, Augustinos AA, Nestel D, Mathiopoulos KD (2014) Genetic changes during laboratory domestication of an olive fly SIT strain 138: 423-432. doi: $10.1111 /$ jen. 12042 